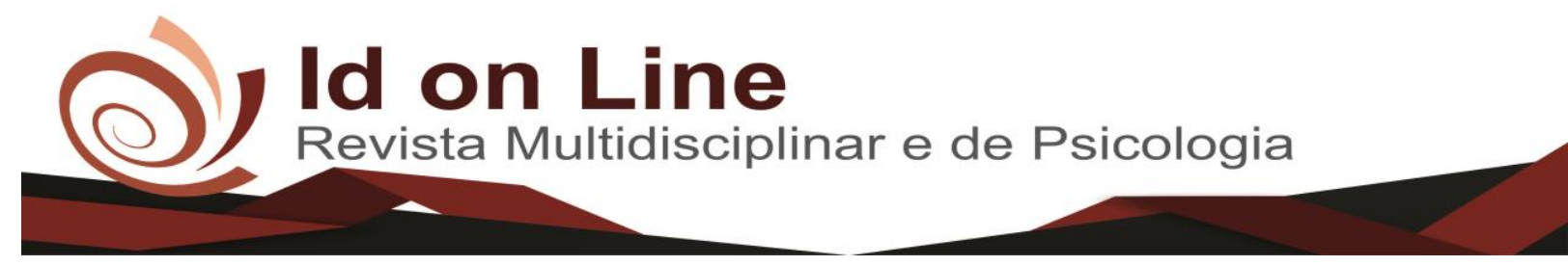

Comment

\title{
Ética e Responsabilidade Socioambiental
}

\author{
Fernanda Coelho de Figueiredo Soares Nascimento ${ }^{1}$; Tiago Gama do Nascimento ${ }^{2}$; \\ Júlio Cezar Costa Ramos ${ }^{3}$; Allan Richards de Melo Nunes Morais ${ }^{4}$; \\ Andrey Tavares da Silva ${ }^{5}$;rancisco Ricardo Duarte ${ }^{6}$
}

\begin{abstract}
Resumo: Uma reorganização de valores passa pelo comportamento ético das organizações, que têm a obrigação de se preocupar com a qualidade de vida dos indivíduos e com a preservação ambiental. O objetivo do presente estudo foi discutir questões relacionadas a ética e a responsabilidade socioambiental. Os resultados levaram a crer que adequar-se à sustentabilidade e à responsabilidade pode ser dispendioso. Porém, a não mudança, a negligência aos problemas sociais e ambientais pode custar muito mais caro no futuro. É urgente uma consciência e união, para que a existência humana seja sustentável no mundo.
\end{abstract}

Palavras-chave: Sustentabilidade, Ética, preservação ambiental.

\section{Ethics and Social and Environmental Responsibility}

\begin{abstract}
A reorganization of values passes through the ethical behavior of organizations, which have the obligation to be concerned with the quality of life of individuals and with environmental preservation. The objective of the present study was to discuss issues related to ethics and social and environmental responsibility. The results have led us to believe that adapting to sustainability and accountability can be costly. However, nonchange, neglect of social and environmental problems can cost much more in the future. There is an urgent need for a conscience and unity so that human existence is sustainable in the world.
\end{abstract}

Keywords: Sustainability, Ethics, environmental preservation.

\section{Introdução}

O tema "ética e responsabilidade socioambiental" surge a partir do momento em que a humanidade se dá conta de que a busca desenfreada e predatória pelo "desenvolvimento" coloca o homem e a natureza como meras ferramentas no processo produtivo. A busca do "ter"

\footnotetext{
${ }^{1}$ Universidade Federal Vale do São Francisco - UNIVASF;

${ }^{2}$ Graduação em Engenharia Civil pela Universidade Federal do Vale do São Francisco, Especialização em Estruturas de Concreto e Fundações pela Universidade Cidade de São Paulo.

${ }^{3}$ Universidade Federal Vale do São Francisco - UNIVASF. Autor Correspondente. Contato: julioccr@gmail.com;

${ }^{4}$ Especialização em Ensino Superior, Contemporaneidade e Novas Tecnologias pela Universidade Federal do Vale do São Francisco. Mestrado em Administração Pública pela UNIVASF;

${ }^{5}$ Graduação em Análise e Desenvolvimento de Sistemas pela Universidade Norte do Paraná, Brasil. Coordenador Técnico da Rede Metropolitana do Vale do São Francisco , Brasil;

${ }^{6}$ Universidade Federal Vale do São Francisco - UNIVASF.
} 
negligencia as necessidades do meio ambiente e o bem-estar social, o que tem causado uma série de transtornos.

Uma reorganização de valores passa pelo comportamento ético das organizações, que têm a obrigação de se preocupar com a qualidade de vida dos indivíduos e com a preservação ambiental. Não só no interior dos seus limites, porque a verdadeira responsabilidade socioambiental está diretamente ligada a uma visão estruturalista, que quer dizer, entender a própria organização como parte de um sistema. Sistema esse que influencia e é influenciado por suas ações.

O objetivo do presente estudo foi discutir questões relacionadas a ética e a responsabilidade socioambiental

\section{Material e Método:}

O método utilizado para a construção do trabalho foi a Pesquisa Bibliográfica. Foram empregados como referência, livros e artigos, mais especificamente: RUSS, 1999; KARKOTLI e ARAGÃO, 2004; LEISINGER e SCHMITT, 2001; NEDEL, 2004; PASSOS, 2004 e, FERREIRA e GUERRA, 2012.

A escolha dos autores se deu por se relacionarem com os temas: ética, organizações, reponsabilidade social e ambiental. E, de forma complementar, outros materiais que pudessem contextualizar e facilitar a compreensão de determinados conceitos que apareceram ao longo da leitura.

\section{Contextualização Histórica}

Segundo Karkotli e Aragão (2004), a partir da revolução industrial, e com o advento do capitalismo, a vida do homem passou a girar em torno do capital. Este tem dedicado sua vida, sua energia e suas habilidades intelectuais na e para a produção de bens e serviços. O dinheiro, em forma de lucro ou remuneração, seria o objeto de troca responsável por mover essa dedicação. 
Ainda segundo os autores, nesse contexto, o elemento humano é considerado apenas “como mais uma peça da engrenagem fabril” (KARKOTLI E ARAGÃO, 2004, p. 17). A preocupação das organizações se restringia ao seu ambiente interno, negligenciando a importância do ambiente externo. A esfera produtiva teria sido a principal preocupação das teorias clássicas da Administração.

Entre as décadas de 50 e 60, a teoria estruturalista passa a ganhar força. Para entender como esse pensamento interfere da mudança de comportamento das organizações, uma breve definição de estrutura:

\begin{abstract}
Uma estrutura pode ser definida como um sistema integrado de elementos. Essa integração se dá de uma maneira específica, qual seja, se um dos elementos sofre uma mudança, todos os outros elementos serão modificados. As partes componentes dessa totalidade sistemática estão relacionadas entre si [...]. Esse sistema não se confunde com a ideia de organização interna de um conjunto (SALES, 2003).
\end{abstract}

Foi a partir das abordagens estruturalistas que se passou a observar que o desempenho das organizações depende de outros elementos que não somente aqueles internos, e passa-se a dar ênfase também ao exterior. $\mathrm{O}$ estruturalismo considera a organização como uma só estrutura, em todos os seus aspectos. Esse enfoque sistêmico enxerga a organização inserida num meio ambiente, de onde são retirados os recursos para desenvolver sua atividade e para onde também é destinado o resultado do seu trabalho. (KARKOTLI E ARAGÃO, 2004). Ou seja, a organização tem o ambiente em que está inserido como meio e como fim de suas atividades.

"A década de 70 marca o início de uma nova discussão no mundo do trabalho, diferente da tradicional que somente versava sobre o lucro e estratégias competitivas" (PASSOS, 2004, p. 163). Para a autora, é nesse período que as organizações passam a se preocupar com suas obrigações sociais. Segundo Nedel (2004), é a partir da década de 1980 que a ecologia humana passa a ser um tema político. O autor cita que profissionais de diversas áreas (filósofos, sociólogos, cientistas, religiosos, urbanistas, organizações não governamentais) passaram a se preocupar com o assunto.

Todos, ainda que por vias diferentes, chegaram à mesma conclusão: o espaço urbano, biótipo humano por excelência, é ao mesmo tempo o meio mais artificial e perigoso. De toda parte surgiram propostas de ações coletivas para controlar os agentes danosos à vida e ao meio ambiente, tais como a poluição atmosférica, a diminuição dos espaços verdes, as deficiências das infraestruturas, a falta de habitações, as epidemias, a criminalidade urbana etc (NEDEL, 2004, p. 135). 
A partir da década de 1990, o assunto ganha visibilidade quando sai do campo teórico e são criados mecanismos para a prática da responsabilidade socioambiental (PASSOS, 2004). Algumas dessas iniciativas são a RIO 92, a certificação SA 8000 (Social Accountablity 8000), as normas internacionais de direitos humanos, uma norma abrangente para a gestão de Responsabilidade Social das empresas chamada AA1000 (Accountability 1000), o pacto global - lançado pela ONU - e o livro verde que, depois, deu lugar ao livro branco, que incentiva as empresas de capital aberto a publicarem seus balanços sociais.

\section{Problemática}

Responsabilidade socioambiental não pode ser considerada apenas como um conceito, mas, sim, como um comportamento, uma prática a ser adotada tanto pelos indivíduos como pelas organizações. Tanto a sociedade quanto as instituições têm estado mais atentas ao tema. Grandes organizações, tais como a ONU (Organização das Nações Unidas e suas ramificações: Unicef, Unesco, FAO, etc), GreenPeace, WWF (World WideFund for Nature), GRI (Global ReportingInitiative), OIT (Organização Internacional do Trabalho) e WFP (World FoodProgramme) têm se formado com o intuito de lidar com problemas e buscar soluções para as questões sociais e ambientais da contemporaneidade.

O modo de produção capitalista e a busca desenfreada pelo "desenvolvimento" têm contribuído para atrair atenção para essa problemática. A acentuação das desigualdades sociais, o esgotamento dos recursos naturais, a poluição, os desastres ambientais, as doenças da modernidade (sejam as físicas causadas pelo trabalho ou pelo ambiente degradado ou as psíquicas como depressão, pânico e ansiedade) têm sido motivos de preocupação para alguns setores da sociedade. Emerge a responsabilização das organizações com o ambiente e o bemestar social, que precisam atualizar seus modelos de gestão para se adaptarem as novas necessidades e exigências coletivas:

Modelos e sistemas de gestão inovadores estão sendo propostos, práticas avançadas de administração são continuamente perseguidas para adaptar as empresas às exigências de uma economia globalizada. [...] O gestor [...] necessita manter no centro de suas atenções a qualidade de vida das pessoas do ambiente próximo e remoto da organização sob sua responsabilidade (KARKOTLI E ARAGÃO, 2004, p. 9).

As questões sociais e ambientais estão inseridas nos interesses de discussão da ética.

Nedel (2004) rejeita a ideia de criação de uma ética nova para a resolução dos problemas 
ambientais. Para o autor, o respeito à natureza e o trato racional do que nela existe (incluindo os animais) deve ser atingido por intermédio do cumprimento dos deveres do homem para com a natureza, considerada por ele como um patrimônio da humanidade.

Russ (1999) estabelece questionamentos pertinentes à reflexão sobre a ética ambiental: "E se a natureza tivesse direitos, se ela nos abrisse a uma concepção inédita da ética? Como compreender a ideia de um direito ético da natureza, da "physis" concebida como realidade digna de respeito?" (RUSS, 1999, p. 155).

\section{Conceitos}

Para que se compreenda a relação entre a Responsabilidade Social e Responsabilidade Ambiental com a Ética, é necessário entender alguns conceitos relevantes. Alguns deles relacionados, outros complementares e alguns até com intersecções. Mas todos importantes para a percepção do tema. São elencados a seguir.

\section{Ecologia}

Nedel (2004) conceitua ecologia como "ciência do hábitat da vida vegetal, animal e humana" (NEDEL, 2004, p. 128). Seu objetivo é estudar a condição da existência dos seres vivos com relação ao meio ambiente/contexto em que estão inseridos. Trata também das características dos indivíduos, e das espécies, e do efeito que os fatores externos, ambientais e tecnológicos exercem sobre eles.

\section{Ética Ambiental}

Ainda segundo Nedel (2004), a ética ambiental "estuda o significado ético das relações do homem com o meio. Aponta a responsabilidade moral do ser humano com respeito à natureza em geral e a outras formas de vida" (NEDEL, 2004, p. 134). Essa disciplina indica para a ameaça que a forma predatória e desenfreada de satisfazer as necessidades artificias representa para o meio ambiente. 


\section{Responsabilidade Social}

Responsabilidade social é uma questão ética que "pressupõe uma atuação eficaz da empresa com todos aqueles que são afetados por sua atividade, sejam diretas sejam indiretas, possuindo um alto grau de comprometimento com seus colaboradores internos e externos" (MOYSÉS, 2001, apud PASSOS, 2004, p.164).

\section{Ambiente Interno}

Podendo ser chamado também de ambiente direto ou operacional, é definido por Karkotli e Aragão (2004) como "aquele que influencia ou é influenciado por ações ou elementos que têm relação direta com as atividades empresariais" (KARKOTLI E ARAGÃO, 2004, p. 20). Fazem parte do ambiente interno os funcionários, dirigentes, acionistas e investidores.

\section{Ambiente externo}

"O ambiente externo ou indireto pode ser compreendido como aquele que não interage diretamente no funcionamento da organização, mas que pode influenciar nas decisões tomadas por seus administradores" (KARKOTLI E ARAGÃO, 2004, p. 20). Fazem parte: os consumidores (mercado atual e potencial), fornecedores, concorrentes, grupos de interesse, mídia, sindicatos e instituições financeiras.

\section{Responsabilidade Social}

Archie Carroll (1979, apud FERREIRA E GUERRA, 2012) propõe um modelo que indica quatro tipos de expectativas que devem ser consideradas quando se fala em responsabilidade social nas organizações. São eles:

i. Economia: a empresa tem que ser lucrativa;

ii. Legalidade: deve obedecer às legislações vigentes;

iii. Ética: fazer o que é certo e evitar danos;

iv. Discricionariedade: contribuir para a comunidade e qualidade de vida.

Afinal, o que é responsabilidade social? Passos (2004) questiona se se trata de uma obrigação legal, de um comportamento ético, de filantropia ou caridade. Ou de novos termos como filantropia empresarial, filantropia estratégica, cidadania empresarial e ética nos 
negócios. "No Brasil, a ideia de responsabilidade social é mais utilizada diretamente relacionada à ação empresarial, lucrativa, podendo incluir ou não ações filantrópicas ou com a comunidade" (PASSOS, 2004, p. 165).

A autora indica que, nos dias atuais, a sociedade possui uma maior percepção do entrosamento que existe entre as esferas pública e privada. Antes, predominava uma concepção de que toda forma de assistência e de serviços que visam o bem-estar social seriam de responsabilidade do poder público; enquanto que, para as empresas, sobrava, apenas, a missão de criar empregos, gerar lucro e pagar seus tributos.

Apesar de algumas empresas acreditarem que ao pagar seus impostos já estão cumprindo sua responsabilidade perante a sociedade, a forma de pensar sobre as obrigações tem se modificado ao longo do tempo. Responsabilidade social não pressupõe apenas agir dentro da legalidade ou qualquer pequena ação que ultrapasse o estabelecido legalmente. "A doutrina da responsabilidade social significa uma transformação radical na concepção da empresa e de seu papel na sociedade" (PASSOS, 2004, p. 165).

Para Ferreira e Guerra (2012) a expressão "Responsabilidade Social” ainda possui uma quantidade variada de interpretações. Enquanto uns acreditam que seja apenas cumprir a obrigação legal, outros a interpretam como um real comportamento eticamente responsável. Para os autores, ela representa um modelo de gestão que supera o legal e o filantrópico.

\footnotetext{
Responsabilidade Social Empresarial é a forma de gestão que se define pela relação ética e transparente da empresa com todos os públicos com os quais ela se relaciona. Também se caracteriza por estabelecer metas empresariais compatíveis com o desenvolvimento sustentável da sociedade, preservando recursos ambientais e culturais para as gerações futuras, respeitando a diversidade e promovendo a redução das desigualdades sociais (INSTITUTO ETHOS, 2012, apud FERREIRA E GUERRA, 2012).
}

Passos (2004) acredita que agir eticamente, de forma esporádica, não faz uma organização socialmente responsável. É necessário que esse seja um comportamento permanente. Para a autora, a responsabilidade social presume compromisso e consciência das organizações para com as mudanças sociais. É indispensável que elas identifiquem que sua obrigação é acima de tudo com os seres humanos e com a construção de uma sociedade mais justa, solidária e honesta, não apenas com seus acionistas e clientes. Passos (2004) define, ainda, a Responsabilidade Social como uma prática moral, orientada pela ética e "que vai além das obrigações legais e econômicas, rumo às sociais, respeitando-se a cultura e as necessidades e desejos das pessoas" (PASSOS, 2004, p. 166). 
A Responsabilidade Social é considerada, pela autora, como uma prática revolucionária. Afinal, coloca em xeque e altera a essência da relação capital e trabalho, na qual o primeiro era prioridade e dominante sobre o segundo. Ela propõe que o ser humano seja o destaque da relação e não mais o lucro e o capital.

A relação entre responsabilidade e ética é exposta de forma clara pela autora:

\begin{abstract}
Pensar em responsabilidade é pensar em ética. Ela implica em compromisso com a humanidade, respeitando os direitos humanos, justiça e dignidade; e com o planeta, comportando-se de forma responsável e comprometida com a sustentabilidade de toda a rede da vida. É uma atitude humana que exige escolha, opção livre e consciente. As pessoas precisam tomar consciência da dimensão de seus atos, a quem eles poderão ser uteis ou prejudiciais e se posicionarem de forma transparente e consequente (PASSOS, 2004, p.167).
\end{abstract}

A prática da responsabilidade social requer respeito e humildade por parte dos seus idealizadores. Faz-se necessário ouvir as demandas das partes interessadas e o envolvimento de todos do ambiente interno da organização: desde os funcionários até os mais altos cargos. São preferíveis as ações mais abrangentes, as que atendam ao maior número de pessoas e atinjam àquelas que tenham menos oportunidades. Esta prática traz consequências positivas para o ambiente organizacional, tais como: benefício à produção, maior motivação e interesse da equipe, um clima organizacional mais saudável, aumento da credibilidade da organização e a preferência dos clientes (PASSOS, 2004).

Contudo, segundo a autora, tais consequências positivas não devem ser a motivação da mudança de postura de uma organização. Há que se considerar a diferença entre a motivação moral, que é aquela pautada na eticidade do agir de forma socialmente responsável; e a motivação instrumental, que é quando a organização se vale das práticas sociais como um diferencial competitivo. Uma falsa organização responsável é aquela que investe em ações que beneficiem o seu ambiente externo enquanto, por outro lado, explora os seus colaboradores.

\title{
Responsabilidade Ambiental
}

Duas vertentes de ética ambiental são apontadas por Nedel (2004): a conservacionista e a preservacionista. A teoria conservacionista considera a natureza como um instrumento, que pode ser explorado e modificado pelo homem, desde que o intuito seja obter o bem-estar para o maior número de pessoas. Já a teoria preservacionista assume um valor próprio à natureza, 
existindo um limite para sua exploração por parte do homem. Assim, este tem que proteger, respeitar, desenvolver e usar seus recursos, sem depredá-la.

Leisinger e Schmitt (2001) não acreditam em superação da pobreza sem desenvolvimento industrial:

Só as pessoas românticas, ou as que não tenham nenhum conhecimento da pobreza
nos países em desenvolvimento, podem achar que a melhoria da qualidade de vida
nesses países seria possível sem um crescimento econômico e sem um
desenvolvimento industrial (LEISINGER E SCHMITT, 2001, p. 88).

Os autores admitem que investimentos em tecnologias de preservação ambiental sejam geradores de custos elevados e sugerem como solução a parceria entre as organizações e a busca de coalizões para que haja transferência ecológica de tecnologia. Os recursos são escassos e as necessidades infinitas, portanto, para a ecologia, a relação custo-eficiência também é muito importante. "O que numa perspectiva ética global logo se torna evidente é perfeitamente possível que crie problemas quando for posto em prática por empresas individuais" (LEISINGER E SCHMITT, 2001, p. 89).

Dentro de uma perspectiva ética, iniciativas empresariais isoladas devem ser exigidas até o limite do que técnica e economicamente é viável. Elas possuem um valor intrínseco - mas para uma melhoria sustentável do status quo ecológico as iniciativas isoladas não possuem senão uma utilidade limitada (LEISINGER E SCHMITT, 2001, p. 89).

Segundo a Comissão Mundial sobre Meio Ambiente e Desenvolvimento, criada pelas Nações Unidas, o desenvolvimento sustentável é aquele: “capaz de suprir as necessidades da geração atual, sem comprometer a capacidade de atender as necessidades das futuras gerações. É o desenvolvimento que não esgota os recursos para o futuro" (O QUE... 2018). Ou seja, diferente do que muitos pensam, desenvolvimento sustentável não é frear ou parar o desenvolvimento, e, sim, conciliar o progresso com o cuidado com o meio ambiente. A definição surgiu como proposta de harmonização entre os dois objetivos que aparentemente são opostos: o desenvolvimento econômico e a preservação ambiental.

É natural que as organizações não sejam inicialmente ecológicas. Normalmente, elas fazem aquilo que delas é exigido, por intermédio de legislações, ou aquilo que é do seu interesse. Os altos custos, em curto prazo, desestimulam e desmotivam práticas voltadas para a preservação ambiental. Mas, no longo prazo, os investimentos voltados à ecologia podem apresentar vantagens econômicas. Ações relativamente simples podem ser relacionadas para melhorar a atuação da empresa frente às necessidades naturais tidas como: redução do consumo 
de energia, redução do consumo de matérias primas não renováveis, diminuição da produção de lixo, substituição de materiais tóxicos e/ou não renováveis por matérias limpas e renováveis e preferência por materiais recicláveis (LEISINGER E SCHMITT, 2001).

Russ (1999) valida a preocupação com as questões ambientais ao afirmar que: "este levar em conta ecológico das mutações do agir humano e da realidade natural é legítimo, como vontade de inscrever os problemas do meio ambiente no coração das preocupações éticas" (RUSS, 1999, p. 156). A autora ressalta que tratar de "direitos do ambiente" pode parecer estranho ou extravagante uma vez que, culturalmente, direitos são associados a seres humanos. Mas a ética ecológica profunda não concorda que esse seja um privilégio apenas do homem; ela reconhece a natureza como um "fim em si", que não deve ser tratada apenas como meio e que possui valor absoluto.

Leisinger e Schmitt (2001) chamam a atenção para a responsabilidade do Estado para os assuntos ambientais. Eles afirmam que apenas o idealismo e crenças pessoais das lideranças empresariais são capazes de gerar iniciativas voltadas para esse fim, o que tornaria a produção de políticas ambientais, por parte das organizações, apenas pontual. Portanto, compete ao poder público legislar e regulamentar tais políticas. Algumas sugestões - como criar estímulos de mercado para a proteção ambiental, conferir durabilidade e conversibilidade às políticas e atribuir aos bens ambientais um preço que reflita sua escassez ou a valorização social de seu uso - são dadas pelos autores.

Esta última sugestão é apresentada, porque Leisinger e Schmitt (2001) consideram que os preços de mercado não refletem plenamente os custos do uso ambiental, não expressam a "verdade ecológica".

Custos de fundamental importância para o emprego e os danos do meio ambiente não transparecem plenamente nos orçamentos das empresas (como não aparecem também nos orçamentos familiares ou do Estado), mas são em sua maior parte transferidos (externalizados) para a sociedade ou para as gerações vindouras (LEISINGER E SCHMITT, 2001, p. 91).

Ou seja, se os preços refletissem de fato o dano que a sua produção causa ao meio ambiente, as empresas se preocupariam mais em minimizar o impacto de suas fabricações. Por exemplo, se um refrigerante envasado numa embalagem PET custasse o equivalente ao tempo que esse material demora a se decompor depois de descartado e ao custo ambiental de se explorar e refinar petróleo, ele seria muito mais caro do que um mesmo refrigerante envasado numa embalagem retornável, por exemplo. Isso tornaria o produto menos competitivo e obrigaria as empresas a procurarem soluções alternativas e mais sustentáveis. 
Outro cuidado para o qual os autores alertam é para a ampla organização e cooperação internacional das políticas ambientais. Os esforços de um país tornam-se inúteis quando outro possui uma legislação menos rigorosa e permite que as empresas transfiram suas produções ou a parte suja delas de um para outro.

Contudo, Russ (1999) traz um alerta para a inversão de valores ("sob o amor à natureza, o ódio aos homens") e uma busca pelo equilíbrio entre a proteção à natureza e à humanidade. "Não é mais o homem que é tomado como centro de referência, mas da natureza ou da vida. Um anti-humanismo se esboça frequentemente, anti-humanismo presente em numerosos movimentos verdes atuais" (RUSS, 1999, p. 157).

\section{Novas questões relacionadas ao tema}

Em 2015, a ONU (Organização das Nações Unidas) lançou a Agenda 2030 para o Desenvolvimento Sustentável. Segundo o preâmbulo do documento:

Esta Agenda é um plano de ação para as pessoas, para o planeta e para a prosperidade. Ela também busca fortalecer a paz universal com mais liberdade. Reconhecemos que a erradicação da pobreza em todas as suas formas e dimensões, incluindo a pobreza extrema, é o maior desafio global e um requisito indispensável para o desenvolvimento sustentável (NAÇÕES UNIDAS, 2015).

A agenda possui uma lista com 17 objetivos e 169 metas de desenvolvimento sustentável que visam estimular ações por parte dos países a partir de parcerias colaborativas para os próximos 15 anos. Os objetivos são: erradicação da pobreza, erradicação da fome, saúde de qualidade, educação de qualidade, igualdade de gênero, água limpa e saneamento, energias renováveis, empregos dignos e crescimento econômico, inovação e infraestrutura, redução das desigualdades, cidades e comunidades sustentáveis, consumo responsável, combate às mudanças climáticas, vida debaixo da água, vida sobre a terra, paz e justiça e parcerias pelas metas.

De forma bem humorada, e destacando a complexidade das ações para que se atinjam os objetivos globais da Agenda 2030, a ONU lançou, em dezembro de 2017, o "Guia da pessoa preguiçosa para salvar o mundo". O guia é para que pessoas comuns possam contribuir para a construção de um mundo melhor por meio de pequenas atitudes nodia a dia. As dicas são divididas em três níveis de complexidade: sofá superstar, herói e heroína da família e pessoal legal do bairro (NAÇÕES UNIDAS, 2017). 
No nível sofá superstar algumas das dicas são: economizar energia, pagar contas online, cobrar das autoridades, não imprimir, apagar as luzes, comprar de empresas sustentáveis, manter-se informado e comprar créditos de carbono.

No nível herói e heroína da família: usar o ar natural para secar a roupa, usar palitos de fósforo, reaproveitar água da chuva, instalar painéis solares, usar aparelhos de energia eficientes, comprar produtos pouco embalados, reciclar, fazer compostagem, comer menos carne, peixe e aves, e tomar banhos curtos.

Para o último nível, o pessoa legal do bairro, algumas das recomendações são: comprar de comerciantes locais, votar de forma consciente, vacinar-se e vacinar os filhos, doar o que não usa, fazer manutenção do carro, utilizar sacolas retornáveis nas compras, andar de bicicleta, de transporte público ou caminhar e comprar de forma inteligente.

\section{Considerações Finais}

Não é mais possível que as organizações ignorem a necessidade de agir de forma responsável com a sociedade e com o meio ambiente. E isso não significa fazer apenas o que lhes é exigido pela legislação e muito menos se ater a políticas internas. É preciso compreender a organização de forma sistêmica, entender que ela é afetada e afeta todo o ambiente ao seu redor. Não existem sistemas isolados.

De forma equilibrada, é preciso cuidar das pessoas e da natureza. Os problemas existem: a poluição, o desmatamento, a extinção das espécies, a violência nas cidades, a fome, a extrema pobreza. Tudo isso é real. E todos são corresponsáveis, pois compõem uma mesma estrutura.

De fato, a mudança de comportamento é sempre custosa. Adequar-se à sustentabilidade e à responsabilidade pode ser dispendioso. Mas a não mudança, a negligência aos problemas sociais e ambientais pode custar mais caro no futuro.

As Organizações não governamentais emergem com a preocupação de controlar os avanços destrutivos e propor soluções aos problemas. Além de estarem dispostas a agir de forma colaborativa com as instituições para atingir seus objetivos. É preciso consciência e união para que a existência humana seja sustentável no mundo. 


\section{Referências}

FERREIRA, Bruna Souza; GUERRA, José Alfredo de Pádua Guerra. Responsabilidade socioambiental: um olhar sistêmico em uma organização estatal. $8^{\circ}$ Congresso brasileiro de sistemas. Revista Gestão \& Conhecimento. Poços de Caldas, MG, PUC,p. 159-180, 2012.

KARKOTLI, Gilson; ARAGÃO, Sueli Duarte. Responsabilidade social: uma contribuição à gestão transformadora das organizações. Petrópolis, RJ: Vozes, 2004.

LEISINGER, Klaus Michael; SCHMITT, Karin. Ética empresarial:Responsabilidade global e gerenciamento moderno. Tradução de Carlos Almeida Pereira. Petrópolis, RJ: Vozes, 2001.

NAÇÕES UNIDAS. Transformando Nosso Mundo: A Agenda 2030 para o Desenvolvimento Sustentável. Traduzido pelo Centro de Informação das Nações Unidas para o Brasil (UNIC Rio). 2015. Disponível em:<https://nacoesunidas.org/pos2015/agenda2030/>. Acesso em: 12 fev.2018.

Guia da pessoa preguiçosa para salvar o mundo. 2017. Disponível em: <https://nacoesunidas.org/guiadopreguicoso/>. Acesso em:25jan. 2018.

NEDEL, José. Ética aplicada: pontos e contrapontos. São Leopoldo, RS: Editora UNISINOS, 2004.

O QUE é desenvolvimento sustentável? Disponível em:<https://www.wwf.org.br/natureza_brasileira/questoes_ambientais/desenvolvimento_sustenta $\mathrm{vel} />$. Acesso em:29jan. 2018.

PASSOS, Elizete. Ética nas organizações. São Paulo: Atlas, 2004.

RUSS, Jacqueline. Pensamento ético contemporâneo. Tradução de Constança Marcondes Cesar. São Paulo: Paulus, 1999. (Coleção filosofia em questão).

SALES, Léa Silveira. Estruturalismo - história, definições, problemas. Revista de Ciências Humanas. Florianópolis, EDUFSC, n. 33, p. 159-188, 2003.

Como citar este artigo (Formato ABNT):

NASCIMENTO, Fernanda Coelho de Figueiredo Soares; NASCIMENTO, Tiago Gama do; RAMOS, Júlio Cezar Costa; ORAIS, Allan Richards de Melo Nunes; SILVA, Andrey Tavares da; DUARTE, Francisco Ricardo. Ética e Responsabilidade Socioambiental. Id on Line Rev.Mult. Psic., 2019, vol.13, n.43, p. 1043-1055. ISSN: 1981-1179.

Recebido: 11/12/2018;

Aceito: $12 / 12 / 2018$ 